\title{
First-principles Study on the Structure and Hydrogen Storage Properties of Na decorated BN Sheet
}

\author{
AN BO ${ }^{1,2 *}$ \\ ${ }^{1}$ School of Physics and Mathematics, Wei Nan Normal University, Weina, China \\ ${ }^{2}$ Center of X Ray Detection and Application of ShaanXi, Weinan, China
}

Abstract: The Na decorated BN sheets have a stable sandwich structure and can be regarded as an excellent hydrogen storage material. With respect to first-principles calculation, the electronic structure, geometric structure, partial density of states, mulliken population and ability of absorbing hydrogen molecules of the Na decorated BN sheet have been investigated. The results show that: (1) The most stable structure is $\mathrm{Na}$ atom adsorption on the top of $\mathrm{N}$ atom, it has the greatest binding energy. (2) $\mathrm{Na}$ decorated $\mathrm{BN}$ sheet can adsorb twelve H2 molecules and the average adsorption energy is $0.530 \mathrm{eV} / \mathrm{H} 2$. (3) The hydrogen storage rate of $\mathrm{Na}$ decorated BN sheet is about $8.943 w t \%$. (4) The adsorbed $\mathrm{H} 2$ molecules have polarization phenomenon.

Keywords: Adsorption Energy, Geometric And Electronic Structure, Partial Density of States, Mulliken Population

\section{Introduction}

With the intensification of the energy crisis, the search for new alternative energy had become the common research goal of scientists in various countries [1]. Hydrogen $\left(\mathrm{H}_{2}\right)$ was widely concerned because of its rich reserves, easy synthesis, clean, non pollution and a series of excellent characteristics. However, the commercial application of hydrogen energy was restricted by the delay in the research of hydrogen storage materials. The ideal hydrogen storage materials must have the following advantages [2]: (1) storage mass density $\geq 6 \mathrm{wt} \%$; (2) dynamic performance of $\mathrm{H}_{2}$ at room temperature (the adsorptive energy of $\mathrm{H}_{2}$ molecule are between 0.2 and $0.6 \mathrm{eV} / \mathrm{H}_{2}$ ); (3) adsorb and release hydrogen repeatedly. To achieve the goals, the researchers focused on the study of alloy hydrogen storage materials [3-5], coordination hydride hydrogen storage materials [6-8] and carbon based hydrogen storage materials [9-11] in recent year. As a kind of hydrogen storage material, carbon based materials (carbon nanotubes, grapheme etc.) have the advantages of large surface area, small density and adjustable aperture. However, the hydrogen adsorption rate of pure carbon based materials was very low $\left(\sim 0.06 \mathrm{eV} / \mathrm{H}_{2}\right)$ [12], which was far from the dynamic requirements for the rapid absorption of $\mathrm{H}_{2}$. Further studies have found that the metal doped or decorated pure carbon based materials could improve the hydrogen adsorption energy. Based on the density functional theory, Seenithurai [13] has studied the hydrogen storage properties of Li-decorated double carbon vacancy graphene (DVG) and this leads to a gravimetric storage capacity of $3.89 \mathrm{wt} \%$, when Li was decorated on both sides of DVG, the gravimetric storage capacity reaches $7.26 \mathrm{wt} \%$, the average adsorption energies were $0.23 \mathrm{eV} / \mathrm{H}_{2}$ and $0.26 \mathrm{eV} / \mathrm{H}_{2}$ respectively. Using the first-principles calculations, Qiu et al. [14] have studied the hydrogen storage of calcium-decorated $\mathrm{BC}_{2} \mathrm{~N}$ sheets doped by Boron or Carbon and found that each $\mathrm{Ca}$ atom could adsorb four hydrogen molecules, the average adsorption energy was about $0.3 \mathrm{eV} / \mathrm{H}_{2}$ and the gravimetric storage capacity of $\mathrm{Ca}$ decorated $\mathrm{BC}_{2} \mathrm{NBC}$ and $\mathrm{BC}_{2} \mathrm{NCN}$ could reach $8.36 \mathrm{wt} \%$ and $8.38 \mathrm{wt} \%$ respectively. BN sheets have a similar structure with graphene so it has become a kind of nanomaterials with potential for hydrogen storage. Chen et al. [15] have

*email:an123bo@yahoo.com,amranbo@126.com 
calculated the hydrogen storage properties of the transition group elements ( $\mathrm{Sc}, \mathrm{V}$ and $\mathrm{Cr}$ ) adsorptive defect $\mathrm{BN}$ sheets, and it could adsorb three $\mathrm{H}$ molecules near the transition atoms, the adsorption energy was between $0.25 \mathrm{eV} / \mathrm{H}_{2}$ and $0.58 \mathrm{eV} / \mathrm{H}_{2}$. The hydrogen storage properties of $\mathrm{Li}$ doped hydrogenated BN sheets have been calculated by Banerjee et al. [16] and the results showed that the hydrogen storage energy was about $0.18-0.3 \mathrm{eV} / \mathrm{H}_{2}$ at $200 \mathrm{~K}$, the gravimetric storage capacity was about $6 \mathrm{wt} \%$. Venkataramanan et al. [17] calculated the hydrogen storage properties of $\mathrm{Ni}$ and $\mathrm{Rh}$ doped BN sheets, which could adsorb three $\mathrm{H}$ molecules around the metal atoms, the adsorption energy of $\mathrm{H}$ molecules were $0.739 \mathrm{eV} / \mathrm{H}_{2}$ and $0.692 \mathrm{eV} / \mathrm{H}_{2}$ respectively.

The geometric structure, electronic structure and hydrogen storage property of Na decorated BN sheet have been studied systematically by the first principles method based on density functional theory in this paper. The results showed that $\mathrm{Na}$ atoms can be stably adsorbed above the top of $\mathrm{N}$ atom, $\mathrm{Na}$ decorated $\mathrm{BN}$ sheet can adsorb 12 hydrogen molecules and the average adsorption energy reached $0.530 \mathrm{eV} / \mathrm{H}_{2}$, the hydrogen storage rate of $\mathrm{Na}$ decorated $\mathrm{BN}$ sheet can reach $8.943 \mathrm{wt} \%$.

\section{Materials and methods}

The calculation was performed by DMol3 codes based on Density Functional Theory (DFT). The exchange-correlation interaction between electrons was described by generalized gradient approximation (GGA) and Becke-threeparameter Lee-Yang-Parr functional (B3LYP). All positions of the atoms were relaxed such that the force on each atom was less than $0.005 \mathrm{eV} / \mathrm{nm}$. The energy minimization was done with the convergence to tolerance energy of $3.0 \times 10-4 \mathrm{eV} /$ atom. SCF tolerance was less than $3 \times 10-5 \mathrm{eV} /$ atom. The Brillouin zone was sampled using $3 \times 3 \times 1$ Monkhorst-Pack mesh of special k-points.

The binding energy between $\mathrm{Na}$ atoms and $\mathrm{BN}$ sheet $\left(E_{b}\right)$ and the average adsorption energy of $\mathrm{H}_{2}$ molecules $\left(E_{a b}\right)$ were defined as follows:

$$
\begin{gathered}
E_{b}=E_{\mathrm{BN}}+E_{\mathrm{Na}}-E_{\mathrm{Na}-\mathrm{BN}} \\
E_{a b}=\left(E_{\mathrm{Na}-\mathrm{BN}}+n E_{\mathrm{H}_{2}}-E_{\mathrm{Na}-\mathrm{BN}+n \mathrm{H}_{2}}\right) / n
\end{gathered}
$$

where $n$ was the number of $\mathrm{H}_{2}$ molecule, $\mathrm{E}_{\mathrm{Na}-\mathrm{BN}}$ was the total energy o the Na-BN sheet and $\mathrm{E}_{\mathrm{Na}}$ $\mathrm{BN}+\mathrm{nH} 2$ was the total energy of the $\mathrm{Na}-\mathrm{BN}+n \mathrm{H}_{2}$ system. $\mathrm{E}_{\mathrm{H} 2}$ was the energy of the single $\mathrm{H}_{2}$ molecule and $\mathrm{E}_{\mathrm{Na}}$ was the energy of isolated $\mathrm{Na}$ atom. $\mathrm{E}_{\mathrm{BN}}$ was the total energy of pure $\mathrm{BN}$ sheet.

\section{Results and discussions}

\subsection{Geometric Structure, Electronic Structure and Binding Energy}

A $3 \times 3 \times 1$ supercell containing nine $\mathrm{B}$ atoms and nine $\mathrm{N}$ atoms with periodic boundary conditions along the $x$ and $y$ axes were used to model the BN sheet. A $2 \mathrm{~nm}$ vacuum layer was built in the $z$ direction in order to eliminate layer-to-layer effects. After optimizing the structure of BN sheet, the B$\mathrm{N}$ bond length was $0.142 \mathrm{~nm}$, it differs from the result of literature [18] $(0.144 \mathrm{~nm})$ by $1.4 \%$. Na atom could adsorb on the bridge site $(\mathrm{B})$, hollow site $(\mathrm{H}), \mathrm{B}$ top site $\left(\mathrm{T}_{\mathrm{B}}\right)$ and $\mathrm{N}$ top site $\left(\mathrm{T}_{\mathrm{N}}\right)$ respectively. The binding energy between $\mathrm{Na}$ atoms and $\mathrm{BN}$ sheet on different adsorption sites were calculated according to equation (1), the results were showed in Table 1. From the Table 1, we found that the binding energy of $\mathrm{Na}$ on different adsorption site were more than the cohesive energy of $\mathrm{Na}$ atom $(1.113 \mathrm{eV})$, it showed that the cluster phenomenon of $\mathrm{Na}$ atoms does not occur and $\mathrm{Na}$ atoms can adsorb the surface of BN sheet stably. The distance between $\mathrm{Na}$ atom and BN sheet was the shortest when $\mathrm{Na}$ atom adsorb on the top of $\mathrm{N}$ atom $\left(\mathrm{T}_{\mathrm{N}}\right)$, at this time, the binding energy between $\mathrm{Na}$ atom and $\mathrm{BN}$ sheet was the largest. It showed that the structure of $\mathrm{Na}$ atom absorb at $\mathrm{T}_{\mathrm{N}}$ site was the most stable. This result was similar to with the literature [16]. 

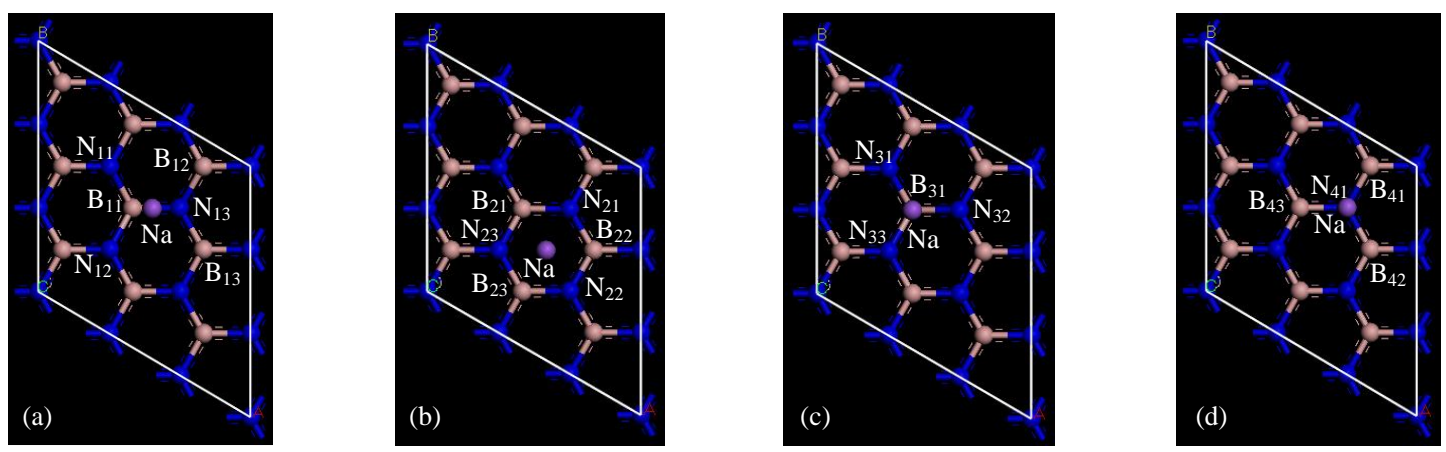

Figure 1. The adsorption structures of $\mathrm{Na}$ decorated $\mathrm{BN}$ sheet (a)bridge site; (b)hollow site; (c)the top of $\mathrm{B}$ site; (d)the top of $\mathrm{N}$ site

Table 1. The adsorption energy and distance of Na-BN and Na-BN $+\mathrm{H}_{2}$

\begin{tabular}{ccccc}
\hline & $\mathrm{B}$ & $\mathrm{H}$ & $\mathrm{T}_{\mathrm{B}}$ & $\mathrm{T}_{\mathrm{N}}$ \\
\hline$E_{b} / \mathrm{eV}$ & 1.807 & 2.129 & 1.870 & 2.371 \\
$d_{\mathrm{Na}-\mathrm{BN}} / \mathrm{nm}$ & 0.231 & 0.201 & 0.218 & 0.198 \\
$d_{a v} / \mathrm{nm}$ & 0.143 & 0.142 & 0.144 & 0.142 \\
$E_{a b} / \mathrm{eV}$ & 0.276 & 0.290 & 0.277 & 0.269 \\
$d_{\mathrm{H} 2-\mathrm{BN}} / \mathrm{nm}$ & 0.272 & 0.265 & 0.270 & 0.281 \\
\hline
\end{tabular}

The density of states (DOS) distribution of $\mathrm{Na}$ atoms at the different adsorption site was shown in Figure 2. For the structure of $\mathrm{Na}$ atom adsorbed on $\mathrm{B}$ site, the seriously overlap between the $\mathrm{Na}$ atom and $\mathrm{BN}$ sheet were in the same energy range from $-0.450 \sim 0.471 \mathrm{eV}, 0.793 \sim 1.426 \mathrm{eV}$ and 2.394 3.292eV (Figure 2a). For the structure of $\mathrm{Na}$ atom adsorbed on $\mathrm{H}$ site, the seriously overlap between the $\mathrm{Na}$ atom and $\mathrm{BN}$ sheet were in the same energy range from 1.990 3.223eV (Figure 2b). For the structure of $\mathrm{Na}$ atom adsorbed on $\mathrm{T}_{\mathrm{B}}$ site, the seriously overlap between the $\mathrm{Na}$ atom and $\mathrm{BN}$ sheet were in the same energy range from $-0.469 \sim 0.441 \mathrm{eV}, 0.487 \sim 1.397 \mathrm{eV}$ and $2.710 \sim 3.298 \mathrm{eV}$ (Figure $2 \mathrm{c}$ ). For the structure of $\mathrm{Na}$ atom adsorbed on $\mathrm{T}_{\mathrm{N}}$ site, the seriously overlap between the $\mathrm{Na}$ atom and $\mathrm{BN}$ sheet were in the same energy range from 1.868 4.230eV (Figure 2d). It was be found that $\mathrm{Na}$ atom $\mathrm{T}_{\mathrm{N}}$ site adsorption structure has the largest overlap range between $\mathrm{Na}$ atoms and $\mathrm{BN}$ sheet. Natural bond orbit (NBO) analysis was used to study the binding energy of the four structures further. It has indicated that the bond of B site's $\mathrm{Na}$ atom and the nearest neighbor B, $\mathrm{N}$ atoms displays hybridization $s^{0.28} p^{0.69} d^{0.03}$, the bond of $\mathrm{H}$ site's $\mathrm{Na}$ atom and the nearest neighbor $\mathrm{B}, \mathrm{N}$ atoms displays hybridization $s^{0.26} p^{0.71} d^{0.03}$, the bond of TB site's $\mathrm{Na}$ atom and the nearest neighbor $\mathrm{B}, \mathrm{N}$ atoms displays hybridization $s^{0.27} p^{0.71} d^{0.02}$, the bond of TN site's $\mathrm{Na}$ atom and the nearest neighbor B, N atoms displays hybridization $s^{0.98} p^{0.02}$. It showed that the hybridization of above four structures are basically the same, but the hybridization of $\mathrm{Na}$ atom on $\mathrm{T}_{\mathrm{N}}$ site adsorption concentrated in $\mathrm{s}$ orbit, this further explains the reason for the stronger binding energy of $\mathrm{Na}$ atom on $\mathrm{T}_{\mathrm{N}}$ site adsorption. 


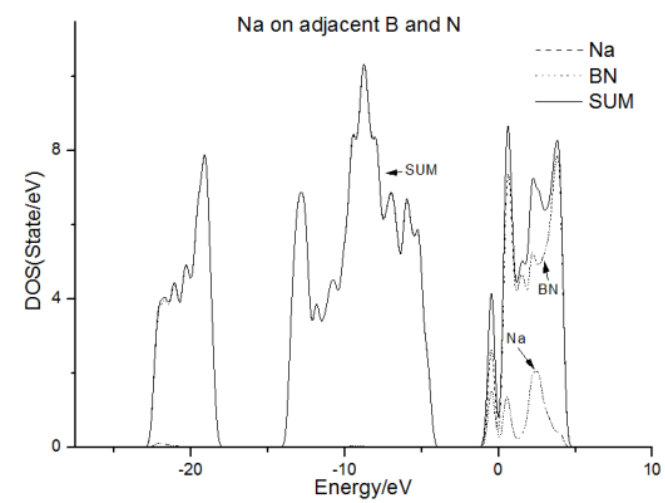

a
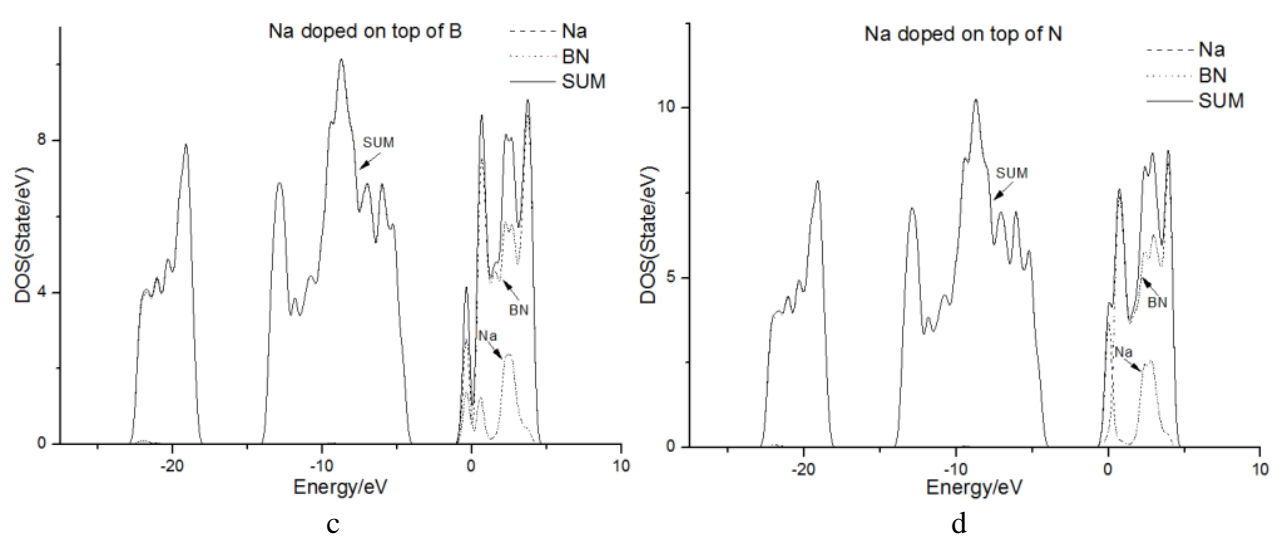

Figure 2. DOS of the different structure of Na adsorption site

\subsection{Adsorption of $\mathrm{H} 2$ Molecules on Pure BN Sheet}

According to the symmetry, there were four possible adsorption sites for the adsorption of pure BN sheet by $\mathrm{H}_{2}$ molecules ( $\mathrm{T}_{\mathrm{B}}, \mathrm{T}_{\mathrm{N}}, \mathrm{B}$ and $\mathrm{H}$ site). Average adsorption energy of $\mathrm{H}_{2}$ molecules with different adsorption sites have been calculated according to the Equation 2 and listed in Table 2. The structures of $\mathrm{H}_{2}$ molecules changed little after geometric optimization. The adsorption energy of $\mathrm{H}_{2}$ molecule at $\mathrm{H}$ site was the strongest, it showed that $\mathrm{H}_{2}$ molecules are more easily adsorbed to the $\mathrm{H}$ site. The results also showed that the adsorption energy of $\mathrm{H}_{2}$ molecules adsorbing pure $\mathrm{BN}$ sheet was low $(\sim 0.27 \mathrm{eV})$. For this reason, metal $\mathrm{Na}$ decorated $\mathrm{BN}$ sheet have been designed to increase hydrogen storage rate.

\subsection{The Adsorption Energy, Geometric Structure and Electronic Structure of $\mathbf{H 2}$ Molecules Adsorbing Na Decorated BN Sheet}

Studies have shown that metal atom can improve the hydrogen storage performance of nanomaterials greatly. Since the structure of TN site's Na atom decorated BN sheet was the most stable, the $\mathrm{H}_{2}$ molecules were placed around the $\mathrm{Na}$ atom. When the number of $\mathrm{H}_{2}$ molecules exceeds fourteen, most of the $\mathrm{H}_{2}$ bonds were broke and form hydrogen atoms, and the adsorption energy tends to rise. Therefore, the geometric structure, electronic structure and hydrogen storage rate of $1 \sim 12 \mathrm{H}_{2}$ molecules adsorbed around decorated TN site's $\mathrm{Na}$ atom have been discussed respectively. Structural parameters and adsorption energy were listed in Table 2. As the number of adsorbed $\mathrm{H}_{2}$ molecules increases: (1) The bond length of $\mathrm{H}_{2}$ molecular did not change much (maximum increase of $1.9 \%$ ), so all of the $\mathrm{H}_{2}$ atoms exist as hydrogen molecules; (2) The distance between the $\mathrm{Na}$ atom and the BN sheet tended to decrease, and the distance between the $\mathrm{H}_{2}$ molecule and the $\mathrm{BN}$ sheet tended to increase. When six $\mathrm{H}_{2}$ molecules were adsorbed, the distance between $\mathrm{Na}$ atom and $\mathrm{BN}$ sheet 
increases, the distance between $\mathrm{H}_{2}$ molecules and $\mathrm{BN}$ sheet decreases, and the average adsorption energy of $\mathrm{H}_{2}$ molecules increases. The reason for this phenomenon was that the six $\mathrm{H}_{2}$ molecules adsorbed around the TN site's $\mathrm{Na}$ atom were just above the six adjacent BN sheet hollow. According to the calculation results in Table 1, the $\mathrm{H}_{2}$ molecule has the largest adsorption energy and the smallest adsorption distance. This may be the reason why the adsorption energy increases when six hydrogen molecules were adsorbed. (3) According to the calculated results of standard deviation of distance between $\mathrm{H}_{2}$ molecules and $\mathrm{BN}$ sheet, we can find that the standard deviation increase as the number of $\mathrm{H}_{2}$ molecules increase. It was indicated that $\mathrm{H}_{2}$ molecules would not be distributed on one plane and tend to be messy. (4) The adsorption energy of $\mathrm{H}_{2}$ molecule was between $\sim 0.83-\sim 0.49 \mathrm{eV} / \mathrm{H}_{2}$ and the distance between $\mathrm{H}_{2}$ molecule and Na-BN sheet was between $\sim 0.33-\sim 0.26 \mathrm{~nm}$, this showed that chemical adsorption between $\mathrm{H}_{2}$ molecules and Na-BN sheet. With the increase of the number of $\mathrm{H}_{2}$ molecules, the adsorption energy of $\mathrm{H}_{2}$ molecules decreases gradually, but the adsorption energy tends to increase when the number of adsorbed molecules exceeds eight. In order to achieve rapid hydrogen absorption and desorption at room temperature, the number of $\mathrm{H}_{2}$ molecules can be adsorbed was twelve at most. The average adsorption energy was $0.530 \mathrm{eV} / \mathrm{H}_{2}$, and the corresponding hydrogen storage rate was $8.9433 \mathrm{wt} \%$.

Table 2. The adsorption energy and structure parameter of $\mathrm{Na}-\mathrm{BN}+\mathrm{nH}_{2}(\mathrm{n}=1 \sim 12)$

\begin{tabular}{cccccccccc}
\hline & $\mathbf{1 H}_{\mathbf{2}}$ & $\mathbf{2} \mathbf{H}_{\mathbf{2}}$ & $\mathbf{4 H}_{\mathbf{2}}$ & $\mathbf{6 H}_{\mathbf{2}}$ & $\mathbf{8} \mathbf{H}_{\mathbf{2}}$ & $\mathbf{1 0 H}_{\mathbf{2}}$ & $\mathbf{1 2 H}_{\mathbf{2}}$ & $\mathbf{1 4 H}_{\mathbf{2}}$ & $\mathbf{1 6 H}_{\mathbf{2}}$ \\
\hline$E_{a b}\left(\mathrm{eV} / \mathrm{H}_{2}\right)$ & 0.826 & 0.595 & 0.501 & 0.521 & 0.483 & 0.515 & 0.530 & 0.553 & 0.555 \\
$d_{\mathrm{H} 2}(\mathrm{~nm})$ & 0.754 & 0.757 & 0.764 & 0.753 & 0.760 & 0.759 & 0.757 & - & - \\
$d_{\mathrm{Na}-\mathrm{BN}}(\mathrm{nm})$ & 0.359 & 0.357 & 0.356 & 0.401 & 0.325 & 0.332 & 0.322 & - & - \\
$d_{\mathrm{H} 2-\mathrm{BN}}(\mathrm{nm})$ & 0.269 & 0.274 & 0.272 & 0.264 & 0.298 & 0.318 & 0.329 & - & - \\
$\mathrm{SE}_{\mathrm{H} 2-\mathrm{BN}}$ & - & 0.000 & 0.003 & 0.002 & 0.066 & 0.083 & 0.066 & - & - \\
$W(\mathrm{wt} \%)$ & 0.812 & 1.610 & 3.170 & 4.681 & 6.145 & 7.565 & 8.943 & - & - \\
\hline
\end{tabular}

To further analyze the interaction between $\mathrm{H}_{2}$ molecules and $\mathrm{Na}-\mathrm{BN}$ sheet, reveal the key factors affecting structural stability, the partial density of states (PDOS) for adsorption of twelve $\mathrm{H}_{2}$ molecules compound has been calculated (Figure 3). The PDOS of Na-BN+12 $\mathrm{H}_{2}$ below the Fermi level was mainly contributed by the $\mathrm{BN}$ sheet and the $\mathrm{H}_{2}$ molecules, and above the Fermi level were contributed by the $\mathrm{BN}$ sheet, $\mathrm{H}_{2}$ molecules and $\mathrm{Na}$ atom. Due to the hybridization between $\mathrm{H}_{2}$ molecules and NaBN sheet, a few electrons of $\mathrm{H}_{2}$ molecule were in $\mathrm{p}$ orbital to form $s^{0.98} p^{0.02}$ hybrid, resulting in a slight increase in the bond length of the adsorbed $\mathrm{H}_{2}$ molecules than the free $\mathrm{H}_{2}$ molecule bond length.

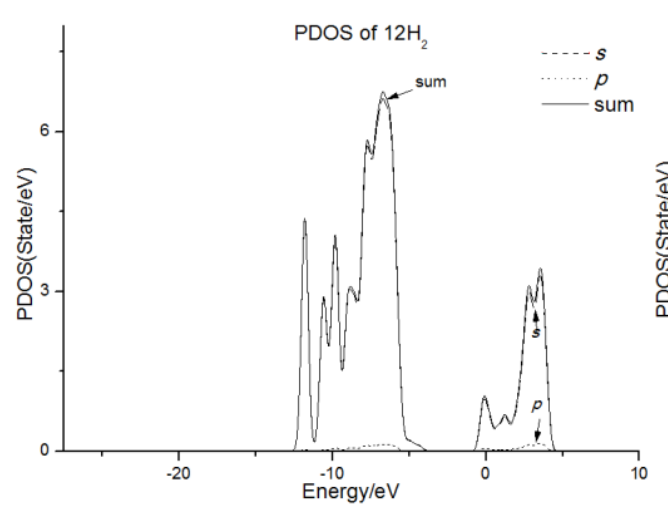

a

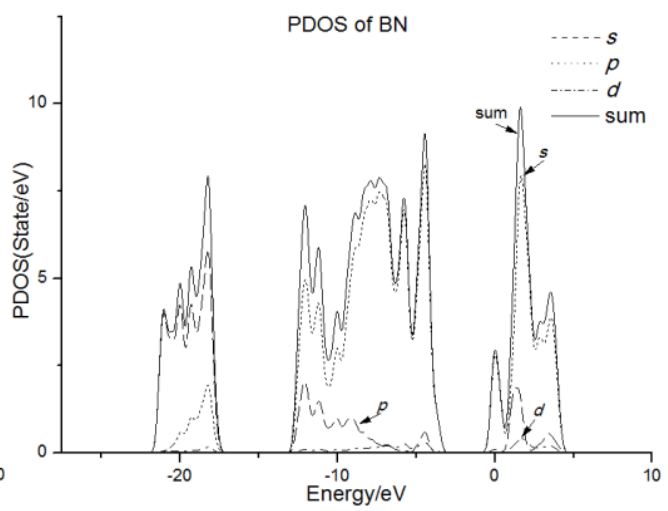

$\mathrm{b}$ 


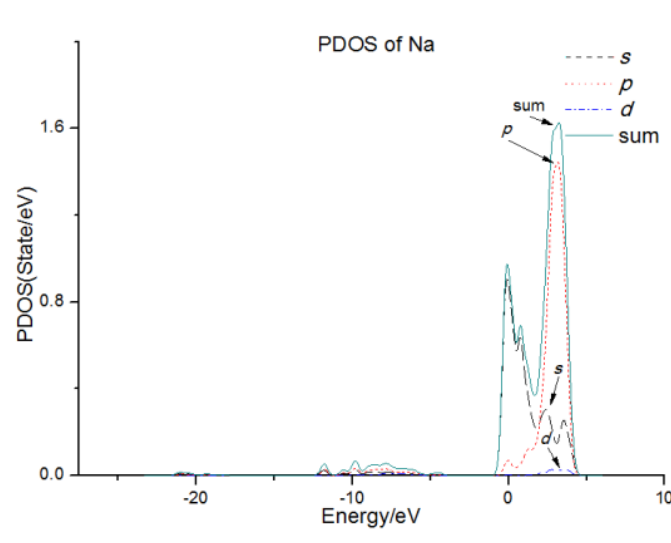

C

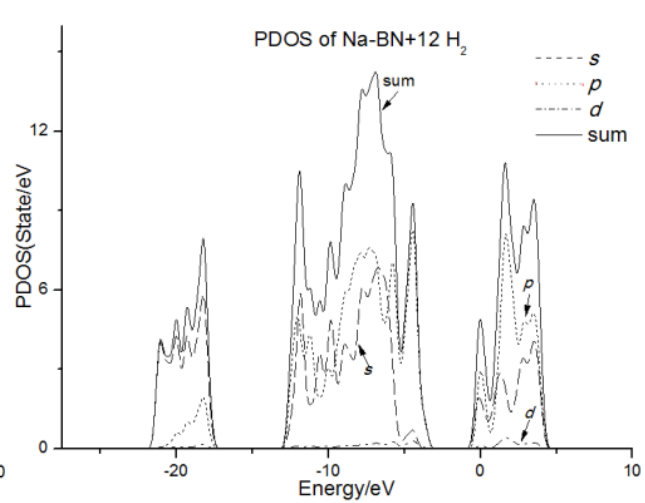

d

Figure 3. PDOS of $\mathrm{Na}-\mathrm{BN}+12 \mathrm{H}_{2}$

\subsection{Mulliken Population Analysis}

In order to study the charge distribution of Na-BN, the Mulliken population has been calculated. The results were showed in Table III. Since the electronegativity of N, B and Na decreases in turn $(3.04>2.04>0.93)$, the $\mathrm{Na}$ and $\mathrm{B}$ atoms in the system were positive charge and the $\mathrm{N}$ atoms were negative charge.

Table 3. Mulliken charge population of Na-BN

\begin{tabular}{|c|c|c|c|c|c|c|c|}
\hline \multirow{2}{*}{ B site } & $\mathbf{N}_{1,1}$ & $N_{1,2}$ & $\mathbf{N}_{1,3}$ & $B_{1,1}$ & $B_{1,2}$ & $B_{1,3}$ & $\mathrm{Na}$ \\
\hline & -0.354 & -0.355 & -0.337 & 0.142 & 0.316 & 0.320 & 0.028 \\
\hline \multirow{2}{*}{ T site } & $\mathrm{N}_{2,1}$ & $\mathrm{~N}_{2,2}$ & $\mathrm{~N}_{2,3}$ & $\mathrm{~B}_{2,1}$ & $\mathrm{~B}_{2,2}$ & $B_{2,3}$ & $\mathrm{Na}$ \\
\hline & -0.342 & -0.345 & -0.340 & 0.309 & 0.322 & 0.316 & 0.152 \\
\hline \multirow{2}{*}{$T_{B}$ site } & $\mathrm{N}_{3,1}$ & $\mathrm{~N}_{3,2}$ & $\mathrm{~N}_{3,3}$ & & $\mathrm{~B}_{3,1}$ & & $\mathrm{Na}$ \\
\hline & -0.354 & -0.358 & -0.354 & & 0.141 & & 0.025 \\
\hline \multirow{2}{*}{$T_{N}$ site } & & $\mathrm{N}_{4,1}$ & & $\mathrm{~B}_{4,1}$ & $\mathrm{~B}_{4,2}$ & $\mathrm{~B}_{4,3}$ & $\mathrm{Na}$ \\
\hline & & -0.336 & & 0.299 & 0.294 & 0.302 & 0.182 \\
\hline
\end{tabular}

By comparing the Mulliken population of Na-BN+12 $\mathrm{H}_{2}$ (Table 4), it was found that the charge of $\mathrm{B}$ and $\mathrm{N}$ atoms did not change much $(<11 \%)$, and the charge of $\mathrm{Na}$ atom increased by $55.5 \%$. Polarization occurs in the charge distribution of $\mathrm{H}_{2}$ molecules, which was why the ability of Na-BN adsorbing $\mathrm{H}_{2}$ molecules was enhanced. Literature [18-24] studied the effect of external electric field on the hydrogen storage performance of graphene modified by $\mathrm{Li}$ atom and reached similar conclusions [25-30].

\section{Conclusions}

With the calculation of hydrogen storage performance of $\mathrm{Na}$ decorated $\mathrm{BN}$ sheet by the first principle, it was found that: (1) The $\mathrm{Na}$ atom has the highest binding energy for the adsorption of $\mathrm{BN}$ sheet on the TN position, and the structure is the most stable. (2) The $\mathrm{H}_{2}$ molecules have the highest adsorption energy for the pure $\mathrm{BN}$ sheet on the $\mathrm{H}$ site. (3) $\mathrm{Na}$ decorated $\mathrm{BN}$ sheet can increase the adsorption energy of $\mathrm{H}_{2}$ molecules significantly. As the number of adsorbed $\mathrm{H}_{2}$ molecules increases, the average adsorption energy decreases. However, when the number of $\mathrm{H}_{2}$ molecules exceeds eight, the average adsorption energy increases. When the number of $\mathrm{H}_{2}$ molecules exceeds twelve, the hydrogen bonds break and form $\mathrm{H}$ atoms. (4) In order to achieve rapid hydrogen absorption and desorption at room temperature, Na-BN sheet can adsorb up to $12 \mathrm{H}_{2}$ molecules. The average 
adsorption energy is $0.530 \mathrm{eV} / \mathrm{H}_{2}$, and the hydrogen storage rate can reach $8.943 \mathrm{wt} \%$.

Acknowledgments: This work was supported by the Wei Nan Normal University's teaching reform project (JG201550).

\section{References}

1.SCHLAPBACH L, ZUTTEL A., Hydrogen-storage Materials for Mobile Applications. Nature., 414, 2001, 353-358

2.KOH G., ZHANG Y. W. PAN H., First-principles Study on Hydrogen Storage by Graphitic Carbon Nitride Nanotubes. Int. J. Hyd. E., 37(5), 2012, 4170-4178

3.BU W. G., ZHANG W., GAO J. L., Improved hydrogen storage kinetics of nanocrystalline and amorphous Pr-Mg-Ni-based PrMg12-type alloys synthesized by mechanical milling. Int. J. Hyd. E., 42(29), 2017, 18452-18464

4.QI Y., ZHANG Y. H., ZHANG W., Hydrogen storage thermodynamics and kinetics of RE-Mg-Nibased alloys prepared by mechanical milling. Int. J. Hyd. Energ., 42(29), 2017, 18473-18483

5.MANIVASAGAM T. G., ILIKSU M., DANILOV, D. L., NOTTEN, P. H., Synthesis and electrochemical properties of binary $\mathrm{MgTi}$ and ternary $\mathrm{MgTiX}(\mathrm{X}=\mathrm{Ni}, \mathrm{Si})$ hydrogen storage alloys. Int. J. Hyd. Energ., 42(37), 2017, 23404-23415.

6.ZHANG J., YAN S., QU H., Alkali metal silanides $\alpha$-MSiH3: A family of complex hydrides for solid-state hydrogen storage. Int. J. Hyd. Energ., 42(17), 2007, 12405-12413

7.SRIVASTAVA A. K. AND MISRA N., Superhalogens as building blocks of complex hydrides for hydrogen storage. Electrochem. Commun., 68, 2016, 99-103.

8.HUMPHRIES T. D., SHEPPARD D. A., BUCKLEY CRAIG E., Recent advances in the 18-electron complex transition metal hydrides of Ni, Fe, Co and Ru. Coord. Chem. Rev., 342, 2017, 19-33,

9.HAN Y. J., PARK S. J., Influence of nickel nanoparticles on hydrogen storage behaviors of MWCNTs. Appl. Surf. Sci., 415, 2017, 85-89,

10.ZZHOU Y. N., CHU W., JING F. L., Enhanced hydrogen storage on Li-doped defective graphene with B substitution: A DFT study. Appl. Surf. Sci., 410, 2017, 166-176

11.CAI Y. X., XIONG J. M., LIU Y. B., Electronic structure and chemical hydrogen storage of a porous sp3 tetragonal BC2N compound. J. Alloy. Compd., 724, 2017, 229-233.

12.AN B., First-principles study on hydrogen storage by calcium-decorated graphene. J. Synth. Crys., 44(1), 2015, 256-261

13.SEENITHURAI S., PANDYAN R. K., KUMAR S. V., Li-decorated Double Vacancy Grapheme for Hydrogen Storage Application: a First Principles Study. Int. J. Hyd. E., 39(21), 2014, 11016-11026 14.QIU N. X., TIAN Z. Y., GUO Y., A first-principle study of calcium-decorated BC2N sheet doped by boron or carbon for high hydrogen storage. Int. J. Hyd. E., 39(17), 2014, 9307-9320

15.CHEN Y., WANG H. M., WANG H. X., Divacancy-assisted transition metal adsorption on the BN graphene and its interaction with hydrogen molecules a theoretical study. Appl. Surf. Sci., 273, 2013, 293-301

16.BANERJEE P., PATHAK B., AHUJA R., First principles design of Li functionalized hydrogenated h-BN nanosheet for hydrogen storage. Int. J. Hyd. Energ., 41(32), 2016, 14437-14446

17.VENKATARAMANAN N. S., KHAZAEI M., SAHARA R., First-principles study of hydrogen storage over Ni and Rh doped BN sheets. Chem. Phys., 359, 2009, 173-178

18.SHEVLIN S. A., GUO Z. X., Hydrogen sorption in defective hexagonal BN sheets and BN nanotubes. Phys. Rev. B., 76, 2007, 024104,

19.ZHANG X., TANG C., JIANG Q., Electric field induced enhancement of hydrogen storage capacity for Li atom decorated grapheme with Stone-Wales defects. Int. J. Hyd. Energ., 41(25), 2016, 10776-10758 
20.ZHANG, T., WU, X., SHAHEEN, S. M., ZHAO, Q., LIU, X., RINKLEBE, J., REN, H., Ammonium nitrogen recovery from digestate by hydrothermal pretreatment followed by activated hydrochar sorption. Chemical Engineering Journal, 379, 2020, 122254.

21.XU, Z., CHEN, X., MENG, L., YU, M., LI, L., SHI, W., Sample Consensus Model and Unsupervised Variable Consensus Model for Improving the Accuracy of a Calibration Model. Appl. Spect., 73(7), 2019, 747-758.

22.YU, D., ZHU, H., HAN, W., HOLBURN, D., Dynamic multi agent-based management and load frequency control of PV/Fuel cell/wind turbine/CHP in autonomous microgrid system. Energy, 173, 2019, 554-568.

23.WANG, P., LI, J. B., BAI, F. W., LIU, D. Y., XU, C., ZHAO, L., WANG, Z. F., Experimental and theoretical evaluation on the thermal performance of a windowed volumetric solar receiver. Energy, 119, 2017, 652-661.

24.LIU, X., ZHOU, X., ZHU, B., HE, K., WANG, P., Measuring the maturity of carbon market in China: an entropy-based TOPSIS approach. J. clean. Prod., 229(1), 2019, 94-103.

25.ZHU, B., YE, S., JIANG, M., WANG, P., WU, Z., XIE, R., WEI, Y. M., Achieving the carbon intensity target of China: A least squares support vector machine with mixture kernel function approach. Appl. Energy., 233, 2019, 196-207.

26.ZHU, B., SU, B., LI, Y., Input-output and structural decomposition analysis of India's carbon emissions and intensity, 2007/08-2013/14. Appl. Energy., 230, 2018, 1545-1556.

27.ZHANG, Y., ZHANG, X., LI, M., LIU, Z., Research on heat transfer enhancement and flow characteristic of heat exchange surface in cosine style runner. Heat Mass Transfer, 55(11), 2019, 31173131.

28.CHEN, S., HASSANZADEH-AGHDAM, M. K., ANSARI, R., An analytical model for elastic modulus calculation of $\mathrm{SiC}$ whisker-reinforced hybrid metal matrix nanocomposite containing $\mathrm{SiC}$ nanoparticles. J. Alloys. Compd., 767, 2018, 632-641.

29.MIREA, R., IORDOC, M., OPRINA, G., RIMBU, G., Processing of Iridium Doped Materials and Experimental Investigation of Their Hydrogen Adsorption Capacity. Rev.Chim., 69(6), 2018, 14681472

30.PANTILE, V., RUSU, E., RADU, A., Performance Comparison between Hydrogen and Hydrogen Addition to Gasoline in an Experimental Single-cylinder Engine. Rev.Chim., 64(3), 2013, 321-325

$\overline{\text { Manuscript received: } 13.03 .2020}$ 
